Click www.researchjournal.co.in/online/subdetail.html to purchase.

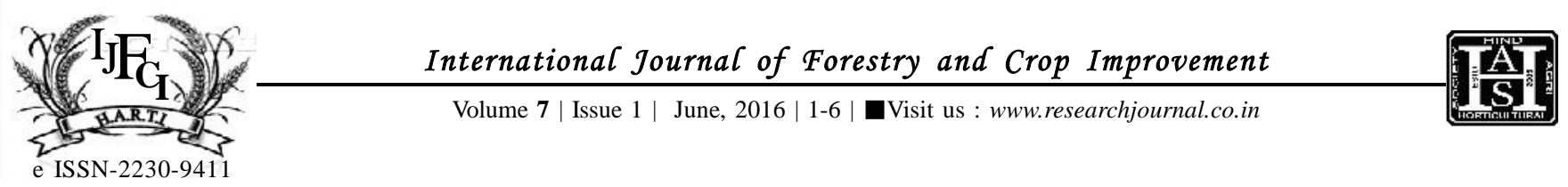

RESEARCH ARTICLE

DOI: $10.15740 / \mathrm{HAS} / \mathrm{IJFCI} / 7.1 / 1-6$

\title{
Heterosis studies in hybrid rice (Oryza sativa L.)
}

\author{
SAMRATH BEDI AND DEEPAK SHARMA
}

\begin{abstract}
To increase production and productivity in this ecosystem, innovative breeding approaches such as heterosis in hybrid rice.Out of these, hybrid rice technology is the proven technology in China and a more practical one to raise production. Hetrosis study comprises of three CMS lines viz., CRMS 31A, IR 58025A and IR79156A and five testers viz., NPT 453-2, NDR 8054 (IR 77768-25-NDR-B-108-14), CR 2330-3-3-2-1-1, NPT 76-8 and PR-115. Indira Sona (hybrid) and Mahamaya (commercial cultivar) .The crosses were tested as line $\mathrm{x}$ tester mating design with two replications. Cross IR 79156A / NPT 76-8 stood for positive significant heterosis over checks for characters grain yield / plant, test weight, pollen fertility percentage, harvest index.
\end{abstract}

KEY WORDS : Heterosis, Line x Tester

HOW TO CITE THIS ARTICLE : Bedi, Samrath and Sharma, Deepak (2016). Heterosis studies in hybrid rice (Oryza sativa L.). Internat. J. Forestry \& Crop Improv., 7 (1) : 1-6, DOI: 10.15740/HAS/IJFCI/7.1/1-6.

ArTiCle ChroniCAL : Received : 26.12.2015; Revised : 01.04.2016; Accepted : 02.05.2016 